\section{Olympic row over sex testing}

\section{Washington}

A PROMINENT Spanish geneticist has refused to participate in a sex testing trial of women athletes participating in the 1992 Olympics in Barcelona, arguing that the simplicity of new testing methods, combined with their inherent fallibility, could lead to increased misdiagnosis of women athletes as men.

Xavier Estivill, of the Cancer Research Institute at the Turan Reinals Hospital in Barcelona, says he has turned down a request by the International Olympic Committee to conduct a trial sex test using gene amplification technology on some 300 of the 3,000 women who will participate in the 1992 Olympics.

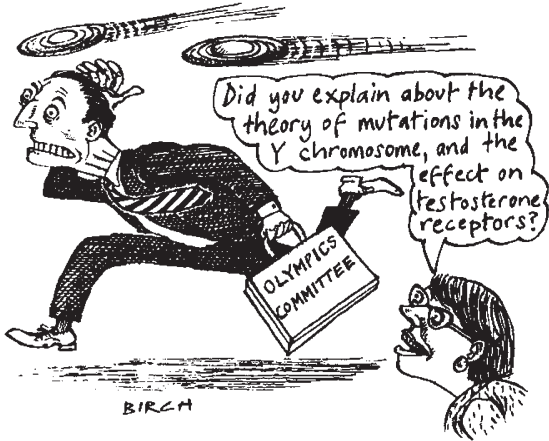

The technology based on polymerase chain reaction (PCR) analysis is, he says, so easy to use that sports-related genetic sex-testing may become commonplace, despite continuing scientific debate about what defines a woman and a dearth of genetic counsellors trained to explain to young female athletes what it means, for example, to have some $\mathrm{Y}$ chromosome motifs in their genetic make-up.

Although the Olympic Committee has been 'sex-typing' women athletes since the 1968 Olympics, medical personnel have until now used only a chromosomal procedure - known as the Barr-body test - that requires experience and sophisticated equipment for diagnosis. Beginning with the 1992 Winter Olympics in Albertville, France, however, the Olympic Committee wants to start sex-typing using the PCR technique, in which primers unique to the $\mathrm{Y}$ chromosome are used to detect the presence of the male-specific genetic material with better than 98 per cent accuracy. The procedure is easy enough to be done by a technician using a prepared kit of primers and common PCR equipment.

Although the Olympic sex tests are designed to screen out athletes with male musculature who are competing as females, a PCR test would also flag genetic variations that provide for no athletic benefit. In one variation, ' $X Y$ females' can have a defect in the $Y$ chromosome which renders it inoperative, and therefore confers no athletic advantage over a normal $\mathrm{XX}$ female.

Estivill argues that the ease with which the PCR sex test can be conducted risks widespread sex testing in the absence of a clear idea of what the results actually mean. Although the Olympic Committee defines women as having two $\mathrm{X}$ chromosomes, there are several alternative chromosomal arrangements that still produce what society considers a woman - even if the scientific community is undecided.

This week the International Olympic Committee is expected to make a decision about what to do in Barcelona. Despite the rejection of such sex typing by many geneticists, the Committee is expected to have little trouble finding some laboratory to do the testing if it decides to continue with the trial.

Christopher Anderson

\title{
Ethics rule reconsidered
}

\section{Washington}

A US ADMINISTRATION official testified last week that he had been surprised by the storm of opposition prompted by a set of new proposed ethics regulations that would restrict the participation of government researchers in professional societies and that the government would redraft the proposal. Steven Potts, director of the Office of Government Ethics, told a congressional hearing on the subject that his office had received more than 1,000 responses to the proposed rules, more than he had seen on any other issue. Scientific societies had organized a letter-writing campaign to oppose the rules, which threatened to prohibit researches at the National Institutes of Health, the Department of
Energy and other government agencies from editing journals, organizing meetings or otherwise participating in society work on government time (see Nature 353, 5;5 September 1991). The societies argued that such participation is an important part of being a working scientist and does not compromise government integrity.

Potts said the regulations had been intended only to codify what his office believed was standard practice. But given the unexpected outcry, his staff was redrafting the rules, and would possibly release them for public comment again. This is expected to delay issuance of the final rules by about three months, to next spring.
Christopher Anderson

\section{Plants, not pandas}

RESEARCHERs working to preserve the genetic stock of rare and endangered plant species are meeting in Washington this week to plan a strategy for putting plant genetic resources on the agenda at the $\mathbf{1 9 9 2}$ 'Earth Summit', the United Nations Conference on Environment and Development to be held in Rio de Janeiro next June. "Plant species on farmers' fields are being lost even faster than endangered animal species. They're not pandas, but they're vitally important", says Geoff Hawtin, director of the International Board for Plant Genetic Resources. He hopes to get a global plant preservation initiative from the Rio conference. Such an initiative would cost some $\$ 300$ million per year - between three and five times current spending on the preservation of agricultural genetic material.

C.A.

\section{Not quite so dumb}

US STUDENTS are nowhere near as bad as international comparisons of test scores suggest, a National Science Foundation (NSF) official writes in the new issue of the National Academy of Engineering journal The Bridge. Well-publicized declines in Standardized Achievement Test (SAT) scores, which are used for university admission, have resulted more from the fact that more students took the test and attended college than the effect of any US educational declines, writes Ira Roteberg, an NSF program director for education. And the sobering results of a 1988 international test for 13-year-olds, which placed the United States last among six countries, are just as likely due to methodological errors stemming from the small and spotty sample size than real differences in education, Rotberg argues.

C.A.

\section{Power of the press}

Once The New York Times notices new research, scientists are more likely to cite it, according to a new study by a University of California, San Diego researcher. Comparing citation counts of research reports published in the New England Journal of Medicine (NEJM), sociologist David Phillips found that work reported by the Times received 73 per cent more citations that other NEJM articles. To eliminate the possibility that this simply reflected the skill of the Times reporters in spotting good research, Phillips examined a threemonth period in 1978 when much of the Times staff was on strike. The editors continued to produce a paper of record, including science coverage, but it was not sold to the public. The articles the Times covered during this period did not score significantly better than others in NEJM, proving, Phillips argues, that scientists are taking their lead from the press.

C.A. 